\title{
Cultural and International Aspects of Innovation and Entrepreneurship in Higher Educational Institutions: Towards a Typology of Learning Universities
}

\author{
Vincent Grèzes \\ University of Applied Sciences Western Switzerland
}

\begin{abstract}
The purpose of this paper is to analyse the international and cultural aspects that academic entrepreneurs must take into consideration and propose a conceptual framework dedicated to the analysis of higher educational institutions (HEI) regarding their international settings and the support or hindrance to academic entrepreneurship. We elaborate on the international and cultural aspects to be considered to successfully undertake an academic entrepreneurship journey, such as cultural, administrative, geographical, and economic distances. We deepen our understanding of the cultural distance by summarizing the most used sociological approaches. Then we discuss the personal and institutional factors that can support or hinder entrepreneurship success, such as cultural sensitivity, cultural awareness, and academic learning organization. Finally, we considered the settings allowing entrepreneurs to develop their cultural sensitivity in the academic context and propose a typology of the HEl regarding their settings and management conditions of entrepreneurship regarding their internationalization and cultural awareness. The results allow university managers and professors or students to identify their organization's maturity in terms of international and cultural awareness towards fostering innovation and entrepreneurship.
\end{abstract}

Keywords: typology, entrepreneurship, innovation, learning organization, distinctive capacities, internationalization, culture, strategic management

JEL classification: 123, L86, L89, L63

Acknowledgments: This study was supported by the Entrepreneurship \& Management Institute and the Business School of the University of Applied Sciences Western Switzerland.

Paper type: Research article

Received: Jul 5, 2021

Accepted: Jul 12, 2021

DOI: 10.54820/IYKW9024 


\section{Introduction}

Entrepreneurship in higher educational institutions can take several forms, considering the types of agents and types of entrepreneurial projects. On the one hand, educational entrepreneurship refers to education businesses that lead to a massive improvement in education (Smith, 2006), where education entrepreneur is the "change agent" who combines business acumen with education expertise (Hess, 2006). On the other hand, academic entrepreneurship is a university faculty that establishes a new company or institution project (Hayter, 2017).

The specificity of international entrepreneurship has been observed as the new and innovative activities that create values and growth in organizations beyond national frontiers (Oviatt, 2005). Therefore, internationalization in the academic entrepreneurship context can be related to several motions of opportunity seeking. As identified in the open innovation processes (Gassmann et al., 2004), the internationalization aspects of academic entrepreneurship can be included in an outside-in process of innovation, enriching a project through the capture of international aspects, an inside-out process of innovation, by transferring ideas to the outside environment, or a coupled process of innovation, by creating alliances of knowledge and developing new projects.

The purpose of this study is to analyse the international and cultural aspects that academic entrepreneurs must take into consideration and propose a conceptual framework for analysing higher educational institutions (HEI) regarding their international settings to support or hinder academic entrepreneurship.

\section{Methodology}

Researchers elaborate on the international and cultural aspects to consider to successfully undertake an academic entrepreneurship journey, such as cultural, administrative, geographical, and economic distances. We deepen our understanding of the cultural distance by summarizing the most used sociological approaches. Then we discuss the personal and institutional factors that can support or hinder entrepreneurship success, such as cultural sensitivity, cultural awareness, and academic learning organization. Finally, we considered the settings allowing entrepreneurs to develop their cultural sensitivity in the academic context and propose a typology of the HEl regarding their settings and management conditions of entrepreneurship regarding their internationalization and cultural awareness.

Based on the previously identified constructs and following the framework of entrepreneurship in peripheral regions developed by Bürcher (2016), we propose a typology, as a "complex theoretical statements that should be subjected to quantitative modeling and rigorous empirical testing" (Doty, 1994, p. 232). The construction of our typology enables us to elaborate ideal-types of higher educational institutions regarding, on the one hand, the vectors of international and cultural sensitivity they propose, and on the other hand, their absorptive capacity.

\section{Results}

In this section, we first present the international and cultural factors that any entrepreneur must consider in an international business development context. Next, we present several settings and management conditions that can support or hinder international and cultural sensitivity in the academic context. Finally, based on the previous elements, we elaborate a conceptual framework of the academic institutions regarding their internationalization and cultural awareness regarding their settings and management conditions of entrepreneurship. 


\section{Internationalization and cultural aspects of entrepreneurship}

On the one hand, Ghemawat (2001) specifies the notions of distances, not only geographical dimensions of internationalization. Indeed, the author proposes several dimensions of distance in international business activities: cultural distance, administrative and political distance, geographic distance, and economic distance. The author recommends analysing those aspects concerning the pertinent industry and observes that industries are not equally sensitive to the different distances. These several types of distance are elements of knowledge regarding international projects that must be taken into consideration by any entrepreneur as key informational success factors.

At a management level, internationalization's success depends on several notions of distances, including cultural distance. These notions of distances are important in the entrepreneurial journey in terms of opportunity and risks management. On the other hand, the notions of culture are numerous in the literature, but there is no common definition. We will focus on two notions of culture that can enlighten the entrepreneur over the concept's diversity and dimensions.

Culture is an invisible distance: According to Hall (1959), "Culture is communication, and communication is culture." (Hall, 1959, p.186). The author developed the theory of proxemics that explains the degree of personal distances maintained by people regarding their social settings and cultural backgrounds (Hall, 1966). According to Hall (1966), the main differences between cultures are related to three dimensions that we summarize in the remainder of this section: the context, the time, the space, then everybody disposes of a situational personality. This consideration leads to four notions of distances, such as the intimate distance or interpersonal distance with contact, the personal distance or interpersonal distance without contact, the social distance is the "limit of the power on other," and the public distance, outside of the circle of individual concern.

Culture is a programming of the mind: According to Hofstede (2001), culture is "the collective programming of the mind that distinguishes the members of one group or category of people from another, where the mind stands for thinking, feeling and acting, with consequences for beliefs, attitudes, and skills." (Hofstede, 2001 , p. 5). Hofstede defines culture as a programming of the mind based on five main cultural dimensions: Power distance, Uncertainty avoidance, Masculinity vs. femininity, Individualism vs. collectivism, Time orientation. These five dimensions are dichotomies that can be used to distinguish between different cultures.

At a personal level, common points through the different dimensions of culture come out of the comparison. Different cultures rely on different values, and the culture is not innate but acquired by the subjects.

\section{The absorptive capacity of international and cultural aspects}

The following section focuses on the attitude of our study subjects: the entrepreneur and the higher educational institution. The subjects' absorptive capacity, such as the ability to value, assimilate, and apply new knowledge for improving organizational learning (Cohen, 1990). Hence, the following sections present conditions of the entrepreneurs and the personal attitudes toward the internationalization and cultural aspects (A) before analyzing the organizational side and its absorptive capacity toward the internationalization and cultural aspects (B).

\section{A. Personal attitude toward internationalization}

To take the chance of the potential of internationalization and its cultural aspects, entrepreneurs and higher education institutions must be aware of several degrees of 
knowledge transfer. To give some direction of thought to measure this degree of knowledge, the next section is dedicated to intercultural sensitivity (1) and cultural awareness (2).

\section{Intercultural sensitivity}

Landis et al. (1996) argue that intercultural sensitivity is crucial for people to live and work with others from different cultural backgrounds. This consideration is particularly important in the context of the coupled process of innovation.

According to Bennett (1993), the development of intercultural sensitivity follows several steps, from ethnocentric stages of resistance to ethnorelative stages of openness. The ethnocentric stages of resistance are: the denial, lowest degree of openness to cultural differences; the defense, with development of sensitivity relative to the denial stage, with a sentiment of the threat emerging of the perception of cultural difference; the minimalization is the last stage of resistance with the attempt to preserve the centrality of one's world view.

With a new way of seeing the cultural difference, begin the ethnorelative stages of openness: the acceptation stage is important because it characterizes the subjectivisation of the cultural aspects, allowing the relativisation of the differences allowing the capacity to imagine other frames of reference than our own; the adaptation is the stage when accepting differences, we can change our behaviors and our way of thinking; finally, the integration is the last stage of openness when a person is capable of adapting to several cultures after a long time of living in various locations.

\section{Cultural awareness}

Numerous studies measured international sensibility through the concept of cultural awareness (Howell, 1982). Indeed, Howell (1982) applied these learning steps to cultural consciousness. Cultural awareness is defined as "learning to work with people from diverse cultural backgrounds, using interpersonal communication, relationship skills, and behavioral flexibility." (Rew, 2003, p. 250). This awareness includes four stages:

- The unconsciousness of incompetence, when the individual does not understand the deficit of knowledge from which he suffers, is not aware of misinterpreting a foreign behavior.

- The awareness of incompetence, when the individual understands that he lacks the competence to complete a task, he is aware of misinterpreting a foreign behavior but knows nothing about it.

- Competence awareness, when the individual understands and knows how to complete a task and can perform it in a strongly conscious way; he reflects on his behavior and consciously tries to modify it to increase its efficiency.

- The unconsciousness of competence, when an individual can perform a task easily without being aware of it, is like second nature; they have practiced and integrated effective communication behaviors.

To take advantage of an international and cultural aspect, the entrepreneur must develop cultural sensitivity and cultural awareness at least at the levels of ethnorelativism with competence awareness. The higher educational institution must support these personal absorptive capacities of international and cultural aspects, such as cultural sensitivity and cultural awareness. The next section will discuss the characteristics of the conditions of absorptive capacity of the academic organization. 


\section{B. Organizational attitude toward internationalization}

Organizational learning theory (Cangelosi, 1965) supports that to be competitive in a changing environment, the company must adapt its actions to achieve its goals and optimize the degree of alignment between expected and achieved results. For learning to occur, the company must make a conscious decision to change in response to the circumstances, consciously link the action to the result, and remember the result.

According to Cangelosi (1965), initial learning takes place at the individual level. However, it becomes organizational learning once the information is shared, formalized, and stored to be transmitted and used.

In the academic context, Dill (1999) describes how universities become "learning organizations" to improve their knowledge creation skills to enhance teaching and learning and modify their behavior to reflect this new knowledge. According to Dill (1999), organizational learning refers to an organization that maximizes the learning opportunities toward organizational changes, and the learning organization is based on the process of learning in the organizational context. The author analyzed the framework proposed by Garvin (1993) regarding learning organizations in the academic context and proposes his five elements of the architecture of the academic learning organization:

- The culture of evidence is a core element in the problem-solving process of improving teaching and learning. Dill (1999) proposes publicly defining and defending student learning measures upon which academic units could base their teaching processes.

- The improved coordination of teaching units is based on the observation that successful problem-solving also requires improved coordination, communication, and accountability structures among faculty members, e.g., curriculum coordinators and faculty committees dedicated to coordinating the teaching and learning within the academic units.

- The learning from others element is seeking out knowledge from others, e.g., organizing study tours to identify curricula innovations or benchmarking professional curricula against international standards.

- The University-wide coordination of "learnings" proposes the development of a pan-university level of coordination and support structure, responsible for allocating funds supporting experiments and innovation in teaching and learning.

- The knowledge transfer was the least in evidence among the case studies and refers to processes and structures encouraging the internal transfer of knowledge for improving core processes.

According to Dill (1999), those architectural elements allow the University to adapt its capacities to new environments better.

The quality of the internationalization process, the basis of the knowledge improvement, relies on the agent's attitude. On the one hand, academic entrepreneurs, such as students and staff, should adopt an ethnorelative attitude, with at least a third level of cultural awareness -a piece of knowledge of the cultural difference. On the other hand, higher education institutions must adopt architectural elements to develop absorptive capacities to enrich their organizational learning process and provide entrepreneurs with a continuously improving and suitable environment to encourage and promote academic entrepreneurship. 


\section{The vectors of international and cultural knowledge}

Internationalization settings among higher educational institutions are vectors of knowledge, based on dedicated processes and characterized by directions -the targeted foreign culture, distances -the cultural diversities- of and speed of knowledge transfer it allows -the degree of awareness gained by using a setting. This section will present some of the international settings used by higher educational institutions (HEI) to promote internationalization by learning from others.

\section{A. HEl settings supporting cultural awareness with mobility}

According to numerous studies, the maximum cultural exposure is gained with longterm studies or work abroad, such as MBA study programs abroad for students (e.g. Tuleja, 2008) or teaching assignments for HEl staff (European Commission, 2014). These experiments also allow participants to emphasize foreign language skills and develop a greater ability to adapt to new situations (European Commission, 2012).

Short-term stays abroad allow moderate cultural exposure. However, they can allow participants better to understand their own culture (Sachau, 2010). It allows students or staff to understand cultural differences and then increase their cultural sensitivity and gain a second level of cultural awareness, the conscience of incompetence (Orahood, 2004).

For the students' cultural exposure, HEl can propose some of the following settings. For 6-12 weeks of studying abroad, the summer semester is the situation where students live on the campus and take several classes. This setting allows moderate cultural exposure. For generally 2-3 weeks, the study tours abroad offer participants to work from city to city and visit sites along the way. This setting allows minimal cultural exposure. For 1-6 weeks, the traineeship abroad is a service-learning experience that includes international travel and volunteer work, integrating coursework and community service.

For the staffs' cultural exposure, HEl can propose some of the following settings. As a traineeship program, staff can participate in summer schools for 2-12 weeks or similar short-term formats with an international audience to benefit from moderate cultural exposure. They can also engage in training assignments, such as job shadowing, for 2- 60 days, group or individual mobility of adult learners, for 2-30 days, and then gain from minimal cultural exposure. Finally, the lower and shorter cultural exposure for staff is the conferences and workshops abroad.

\section{B. HEl settings supporting cultural awareness without mobility}

Some studies underline the belief that increases in intercultural sensitivity can be achieved through education and training without the need for foreign travel (Altschuler, 2003; Paige, 2004). Also, recent developments establish that "Internationalization at Home" is a set of international and intercultural dimensions within domestic learning environments that allows moderate cultural exposure (Beelen et al., 2015; Leung, 2017). The impacts on the participants will therefore vary depending on the activity.

Long-term students' internationalization-at-home opportunities are based on peer learning with distant friends, peer tutoring, cooperative learning, and peer collaboration with mutuality of engagement. These methods allow moderate cultural exposure (Carlson, 2017).

Long-term staffs' internationalization-at-home possibilities are based on incoming staff mobility, such as hosting teachers and educators training for 10 to 365 days (Brewer, 2012). 
Short-term internationalization-at-home possibilities of cross-cultural training sensitivity for students are based on case studies, experiential approaches using a simulation game, and a lecture-based, cognitive presentation (Davies, 2015). These methods allow minimal cultural exposure but offer a cultural analysis-oriented approach. Students can also gain intercultural awareness through group activities in the international classroom or intercultural-competence courses at home (i.e., local immersion within their community). Those exercises allow moderate cultural exposure (Crose, 2011).

Short-term internationalization-at-home possibilities of cross-cultural training sensitivity for staff are the invited experts, for 2-60 days, and invited staff from enterprises. Those settings offer minimal cultural exposure but allow a good knowledge flow regarding the expertise of the guest.

Those different vectors of intercultural sensitivity among students and staff are variable according to the distance their cover (mobility, non-mobility, and specific cultural distances), the intensity of cultural awareness they allow (minimal, moderate, and maximal cultural exposure), the agent they concern and the time they require to transmit them a knowledge.

\section{Construction of the conceptual framework}

Based on the previous constructs and the framework of entrepreneurship in peripheral regions developed by Bürcher (2016), we propose a typology (Doty, 1994) of higher educational institutions ideal types regarding, on the one hand, the vectors they propose, and on the other hand, their absorptive capacity.

Previous sections show that the varying capacity of $\mathrm{HEl}$ and entrepreneurs students and staff, to create and sustain different types of international settings influence academic entrepreneurship. On the one hand, those settings are based on vectors that higher educational institutions established, and on the other hand, on the absorptive capacity of the institution. Finally, the correlation of these two variables allows us to build an institutional typology for an international perspective of academic entrepreneurship in higher education (Figure 1).

\section{Discussion: Typology and its potential implications}

According to previous sections, we can deduce that the competitiveness of $\mathrm{HEl}$ in the field of academic entrepreneurship based on international and cultural aspects depends on their ability to develop vectors of cultural sensitivity and their absorptive capacity to sustain their competence as an academic learning organization. The typology enables to identify of four HEl ideal types:

- Type- $7-H E I$ is the less developed institution regarding the international vectors and the architectural elements of absorptive capacity. This type of institution only proposes vectors that allow minimal or moderate cultural exposure and does not dispose of learning processes to capitalize upon its learnings.

- Type-2-HEl is a relatively weak environment for academic entrepreneurship. It disposes of weak international vectors, allowing minimal or moderate cultural exposure, such as the short-term study of traineeship abroad or groups learning at home. Therefore, this type of institution sets up strong absorptive capacity such as coordination elements through teaching units and the university, or evidence mechanisms to assess students' learning evolution.

- Type-3-HEI is a relatively good environment for academic entrepreneurship from students and staff but will not capitalize upon their learnings. Indeed, this type develops strong vectors relative to mobility and non-mobility settings of internationalization but disposes of a weak absorptive capacity and cannot 
enrich itself from this context. Settings and accumulated knowledge are dispersed and suffer from a lack of coordination between the teaching units and the institution.

- Type-4-HEl appears to be the most competitive institution with strong internationalization vectors, allowing different degrees of cultural exposure (minimal to maximal cultural exposure), such as mobility programs for students and staff and internationalization-at-home programs for students and staff. It develops strong architectural elements of an academic learning organization, such as a developed culture of evidence, improved coordination at the levels of the teaching units and the university-wide, and learning from other elements. This kind of institution will be the most adaptative to its environment, and it will offer the most supportive context for academic entrepreneurship.

Figure 1

An institutional typology for an international perspective of academic entrepreneurship in higher education

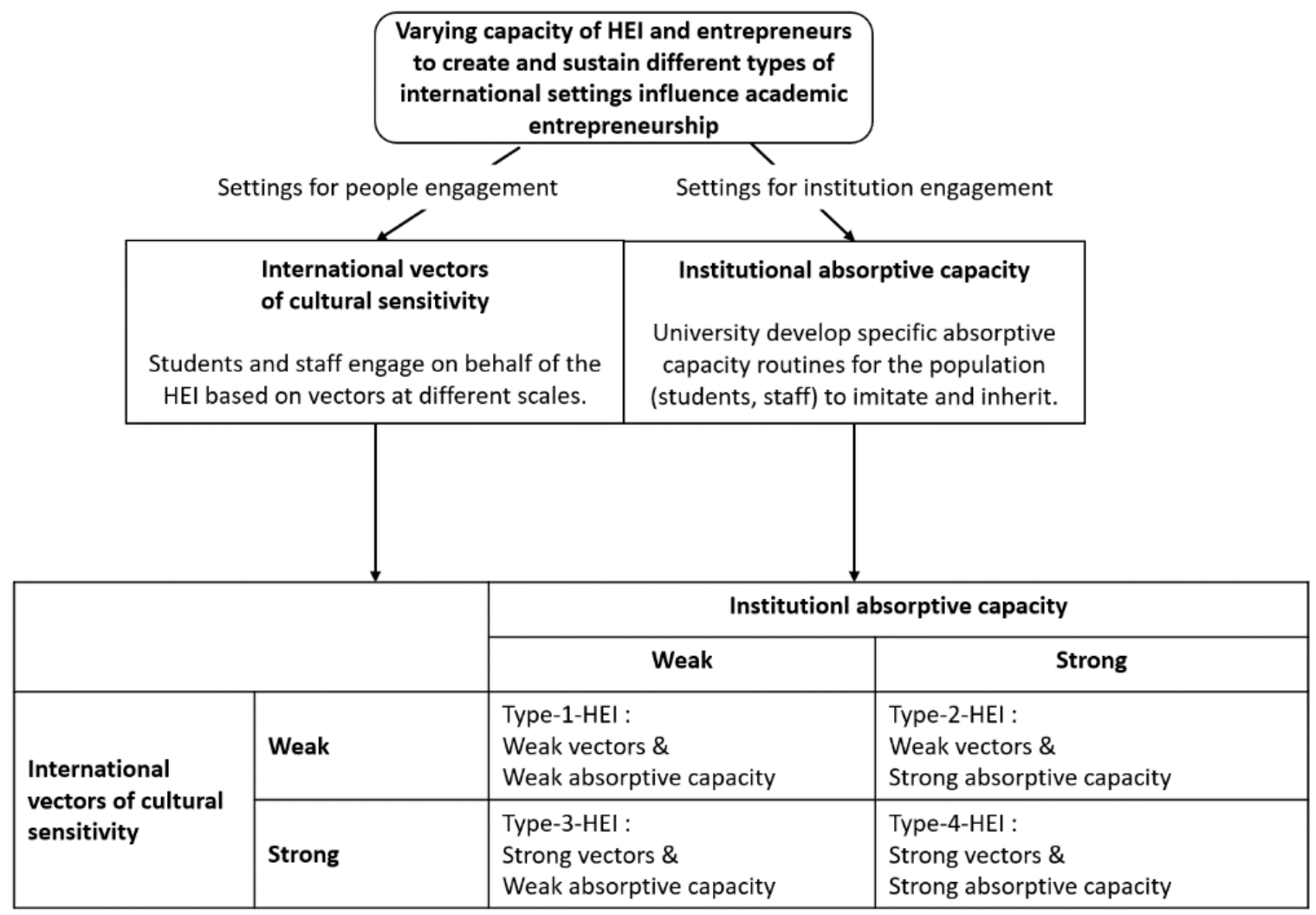

Source: Author's contribution

\section{Conclusion}

In this paper, we first presented the international and cultural factors that any entrepreneur must consider in an international business development context. At a management level, we saw that internationalization's success depends on several notions of distances, including cultural distance. At a personal level, we saw that different cultures rely on different values, and the culture is not innate but acquired by the subjects.

Secondly, we discussed settings and conditions that support or hinder the international and cultural sensitivity of the entrepreneur in the academic context. We saw that the quality of the internationalization process relies on the attitude of 
the agents. On the one hand, academic entrepreneurs, such as students and staff, should adopt an ethnorelative attitude, with at least a third level of cultural awareness -a piece of knowledge of the cultural difference. On the other hand, higher education institutions must adopt architectural elements to develop absorptive capacities to enrich their organizational learning process and provide entrepreneurs with a continuously improving and suitable environment to encourage and promote academic entrepreneurship.

Then, we considered the conditions and vectors of internationalization and cultural aspects in the context of academic entrepreneurship. We identified several settings that HEl can set up to promote intercultural sensitivity among students and staff. Those different vectors are variable according to the distance they cover (mobility, non-mobility, and specific cultural distances), the intensity of cultural awareness they allow (minimal, moderate, and maximal cultural exposure), the agent they are concerned with, and the time they require to transmit their knowledge.

Finally, we proposed a conceptual framework of the academic institutions regarding their settings and management conditions of entrepreneurship related to their internationalization and cultural awareness. The subsequent ideal types allow university managers, professors, and students to identify their organization's maturity in international and cultural awareness towards fostering innovation and entrepreneurship.

\section{References}

1. Altschuler, L. S. (2003), "Assessing changes in intercultural sensitivity amongphysician trainees using the Intercultural Development Inventory", International Journal of Intercultural Relations, Vol. 27 No. 4, pp. 387-401.

2. Beelen J., Jones, E. (2015), "Redefining Internationalization at Home", in Curaj A., Matei L., Pricopie R., Salmi J., Scott P. (Eds.), The European Higher Education Area, Springer, Cham.

3. Bennett, M. J. (1993), "Towards Ethnorelativism: A Development Model of Intercultural Sensitivity", in Paige, R. M. (Ed.), Education for the Intercultural Experience, Intercultural Press, Yarmouth.

4. Brewer, E. L. (2012), "Internationalization of the curriculum", in Deardorff, H. (Ed.), The Sage handbook of international higher education, Sage, Thousand Oaks, pp. 245-266.

5. Bürcher, S. H. (2016), "Entrepreneurship in peripheral region. A relational perspective", in Mack, E. A. (Ed.), Geographies of Entrepreneurship, Routledge, New York, pp. 143164.

6. Cangelosi, V. E. (1965), "Organizational Learning: Observations Toward a Theory", Administrative Science Quarterly, Vol. 10 No. 2, pp. 175-203.

7. Carlson, E. S. (2017), "Nursing as universal and recognisable: Nursing students' perceptions of learning outcomes from intercultural peer learning webinars: A qualitative study", Nurse education today, Vol. 57, pp. 54-59.

8. Cohen, W. M. (1990), "Absorptive capacity: A new perspective on learning and innovation", Administrative Science Quarterly, Vol. 35 No. 1, pp. 128-152.

9. Crose, B. (2011), "Internationalization of the Higher Education Classroom: Strategies toFacilitate Intercultural Learning and Academic Success", International Journal of Teaching and Learning in Higher Education, Vol. 23 No. 3, pp. 388-395.

10. Davies, S. C. (2015), "The development of intercultural competency in school psychology graduate students", School Psychology International, Vol. 36 No. 4, pp. 375-392.

11. Dill, D. (1999), "Academic accountability and university adaptation: The architecture of an academic learning organization", Higher Education, Vol. 38, pp. 127-154. 
12. Doty, D. G. (1994), "Typologies as a Unique Form of Theory Building: Toward Improved Understanding and Modeling", The Academy of Management Review, Vol. 19 No. 2, pp. 230-251.

13. European Commission (2012), Youth on the move - Europe supports young people, Publications Office of the European Union, Luxembourg.

14. European Commission (2014), The Erasmus Impact study, Publications Office of the European Union, Luxembourg.

15. Garvin, D. A. (1993), "Building a learning organization", Harvard Business Review, Vol. 71 No. 4, pp. 78-84.

16. Gassmann, O., Enkel, E. (2004), "Towards a theory of open innovation: three core process archetypes", Proceedings of the R\&D Management Conference, Lisbon, Portugal.

17. Ghemawat, P. (2001), Distance still matters, The hard reality of global expansion, Harvard Business Review.

18. Hall, E. T. (1959), The Silent Language, Doubleday and Co, New York.

19. Hall, E. T. (1966), The Hidden Dimension, Doubleday, Garden City, N.Y.

20. Hayter, C. L. (2017), "Who is the academic entrepreneur? The role of graduate students in the development of university spinoffs", The Journal of Technology Transfer, Vol. 42, pp. 1237-1254.

21. Hess, F. M. (2006), "Entrepreneurship, Risks and Reinvention", in Hess, F. M. (Ed.), Educational Entrepreneurship: Realities, Challenges, Possibilities, Harvard Education Press, pp. 1-21.

22. Hofstede, G. (2001), Culture's consequences, Sage Publications, London.

23. Howell, W. S. (1982), The empathic communicator, Wadsworth, Belmont, CA.

24. Landis, D., Bhagat, R. S. (1996), Handbook of intercultural training, Sage, Thousand Oaks, CA.

25. Leung, D. C. (2017), "Exploring research cultures through internationalization at home for doctoral students in Hong Kong and Sweden", Nurs Health Sci., Vol. 19 No. 4, pp. 525-531.

26. Orahood, T. (2004), "The Impact of Study Abroad on Business Students' Career Goals", Frontiers: The Interdisciplinary Journal of Study Abroad, Vol. 10 No. 1, pp. 117-130.

27. Oviatt, B. M. (2005), "Defining international entrepreneurship and modeling the speed of internationalization", Entrepreneurship Theory and Practice, Vol. 29 No.5, pp. 537554.

28. Paige, R. M. (2004), "Assessing the impact of a strategies-based curriculum onlanguage and culture learning abroad", Frontiers: The Interdiscipli-nary Journal of Study Abroad, Vol. 10, pp. 253-276.

29. Rew, L. B. (2003), "Measuring cultural awareness in nursing students", The Journal of Nursing Education, Vol. 42 No. 6, pp. 249-257.

30. Sachau, D. B. (2010), "Three Models for Short-Term Study Abroad", Journal of Management Education, Vol. 34 No. 5, pp. 645-670.

31. Smith, K. P. (2006), "What Is Educational Entrepreneurship?", in Hess, F. M. (Ed.), Educational Entrepreneurship: Realities, Challenges, Possibilities, Harvard Education Press.

32. Tuleja, E. (2008), "Aspects of Intercultural Awareness Through an MBA Study Abroad Program: Going "Backstage"', Business Communication Quarterly, Vol. 71 No. 3, pp. 314-337. 


\section{About the author}

Vincent Grèzes, Ph.D., works as an associate professor of innovation management and strategic and international management at the University of Applied Science Western Switzerland (HES-SO) in Sierre, Switzerland, and is director of the competitive intelligence track at the HES-SO Master of Integrated Innovation for Product \& Business Development in Lausanne, Switzerland. He received his Ph.D. in economic and strategic intelligence from the Faculty of Law and Political Science of the University of Lyon 3, France. His main research interests are competitive intelligence, shared values, business model innovation, and collaborative and open innovation. The author can be contacted at vincent.grezes@hevs.ch. 